\title{
Teología de las comunidades eclesiales de base en América Latina
}

\author{
José María Castillo, \\ Centro de Reflexión Teológica, \\ San Salvador.
}

\section{Introducción}

Desde hace algún tiempo (no sabría precisar cuánto), se viene hablando de crisis en la vida de las romunidades eclesiales de base que, desde hace unos treinta años, existen en numerosos países de América Latina. Se dice que ya hay menos comunidades que antes. Se dice también que las que quedan tienen menos vitalidad que en años pasados. Y se dice, sobre todo, que el fenómeno de las comunidades de base en la Iglesia está de vuelta; o sea, que ha sido una moda pasajera, que tiene los días contados. Las aguas vuelven a su cauce. Y la Iglesia, piensan algunos, está de nuevo empezando a ser lo que fue siempre: una institución bien organizada a partir del clero, en la que el papa, los obispos y los sacerdotes imparten la doctrina, dan las consignas y toman las iniciativas, mientras que los fieles aprenden, obedecen y reciben los auxilios espirituales que les imparten los "hombres de Iglesia". Es decir, lo de toda la vida. Como tiene que ser. Pasó, por tanto, el sarampión de la "Iglesia popular". Y las cosas vuelven a estar como Diọs manda. Esto, poco más o menos, es lo que piensan algunos, quizá bastantes, aunque no lo digan asł, tal como yo lo acabo de describir rápidamente.

Ahora bien, a mI me parece que quienes piensan y dicen esas cosas, en el fondo, lo que piensan y dicen es que todo lo de las comunidades de base no ha pasado de ser un fenómeno sociológico circunstancial y, por tanto, un hecho transitorio sin más importancia. Y aqus es donde está, según creo, el nudo de la cuestión. Porque, para decirlo claramente y desde el primer momento, el nacimiento, progreso y vida de las comunidades eclesiales en América Latina ha sido, y sigue siendo, un acontecimiento teologico de primera magnitud y cuyas consecuencias, para el futuro de la Iglesia, serán sin duda más decisivas de lo que algunos imaginan. 
Por supuesto -y para evitar suspicacias inútiles desde ahora- quiero dejar claro que las comunidades eclesiales de base en América Latina jamás han puesto en duda ( $y$ menos aún negado) la estructura jerárquica de la Iglesia y la teología en que se fudamenta esa estructura. Con esto quiero decir que las comunidades, ni en su teoría ni en su praxis, por lo que yo sé, nunca han pretendido constituirse en Iglesia y mucho menos en grupos sectarios al margen de la autoridad del papa. de los obispos y de sus colaboradores los presbíteros. Al afirmar esto, no me baso en teorías o en papeles, sino en hechos: la historia de las comunidades demuestra que siempre han querido permanecer en comunión y en diálogo con la jerarquía eclesiástica; y ésa siguc siendo su postura fundamental en este momento. Por lo tanto, el acontecimiento teologico, al que antes he hecho alusión, no consiste en que las comunidades de base hayan pretendido organizar una Iglesia ácrata o acélala; o sca, una Iglesia sin estructura, sin gobierno, sin autoridad. Porque las comunidades han sabido y saben muy bien que la Iglesia de Jesucristo es esencialmente apostólica; y la apostolicidad incluye ła sucesión episcopal con todo to que eso comporta desde el punto de vista de la dognática y desde el punto de vista de la pastoral.

Pues bien, si las cosas son así, entonces, ¿por qué hablar de un "acontecimiento tcológico de primern magnitud"'? Si las comunidades piensan y actúan como acabo de decir, en realidad. ¿qué novedad reológica han aportado? ¿No es repetir lisa y llanamente to que siempre se dijo en la Iglesia y lo que siempre se hizo en la Iglesia? Sf y no. Esta es la cuestión. Sí, porque efectivamente las comunidades eclesiales de base en América Latina han permanecido y permanecen dentro de la más estricta orlodoxia eclesial. No, porque esas comunidades han hecho posible y han rcalizado de facto un acontecimiento teológico tan nuevo y tan profundo, a la vez, que seguramente aún no estamos en condiciones de analizar y medir toda su envergadura y todas sus consecuencias. Esto es to que me propongo presentar en este trabajo.

Pero antes quiero hacer una advertencia importantc. He dicho que se trata de un acontecimiento reológico. Cuando digo esto, no hablo simplemente de una "teología práctica", que eso, ni más ni menos, es la teología pastoralı. Por supuesto. las comunidades eclesiales de base han sido y son una experiencia pastoral, eso es evidente. En ese sentido. se puede y se debe afirmar que el

1. Así lo alïrma literalmente K. Ralıner, uno de los representantes más significativos de la "tcología pastoral". Cfr. K. Rahner y H. Vorgrimler, Diccionario Teológico, Barcclona 1970, pp. 527-528. Es la orientación básica que sigue la obra fundamental de F. X. Arnold, F. Klostermann, K. Rahner, V. Sclurr y L. M. Weber, Handbuch der Pastoraltheologié, en seis volúmenes (1964-1972). Para una información básica sobre la Jisioria y signilicado de la "lcología pastoral", véase el artículo de F. J. Calvo. "Tcologfa pastoral". en C. Floristán y J. J. Tamayo, Conceptos fundamentales de pastoral. Madrid. 1983, pp. 716-729, con bibliografía en pp. 278-729. 
acontecimiento teológico, al que aqui me refiero, ha brolado de la praxis. Y por eso, es "teología acerca de la autorrealización de la Iglesia como actuación salvífica de Dios sobre el mundo", según la conocida y acerlada formulación de K. Rahner ${ }^{2}$. Pero cuando hablo aquí de acontecimiento teológico, me refiero a algo que va más tejos o, si se quierc, mís a la raíz de las cosas. Lo que las comunidades eclesiales de base nos han venido a enseñar no es una nueva modalidad o aplicación de la leología pasioral, sino un nuevo modo de hacer teología o, más propiamente, un nuevo método teológico. Y hablo de teología en el sentido más estriclo e incluso más restringido de la palabra. Es la inteligibilidad de la fe lo que está en juego (fides quacrens intellectum). Porque lo que afirmo y defiendo es que las comunidades eclesiales de base han sido y siguen siendo, en sí mismas, una leología nueva, cs decir, una nueva miınera de entender la fe $y$, por tanto, una nueva teoría. Seguramentc esto explica el hecho de que, en Europa, donde más ha florecido la "tcología pastoral"?. tal teologia no haya desencadenado ni especiales inquictudes ni conflictos llamalivos, mientras que de sobra sabemos hasta qué punto el hecho teológico, que han sido y son las comunidades de base en América Latina, ha inquictado a teólogos, jerarcas eclesiásticos e incluso a amplios seclores de la opinión pública en la Iglesia. Señal patente de que algo nuevo, muy distinto a lo antcrior, está ocurriendo en la teologia; algo que seguramente toca fondo. Sin duda alguna, una nueva y simple práclica pastoral no remueve tantos fondos, ni por supuesto desencadena tanto alboroto. Por eso me parece imporlante y hasta urgenle precisar, en la medida de lo posible, en qué sentido y hasta qué punto las comunidades eclesiales de basc constituyen un acontecimiento teológico enteramente nuevo en la Iglesia. Lo que acabo de decir se comprenderá mejor al final, cuando saque las consecuencias del análisis que voy a intentar realizar a continueción.

\section{Una teología que brota de la vida}

La teología se ha entendido tradicionalmente, y se sigue entendiendo, como "ciencia de la fe" (intellectus fidei)4. Al decir esto, no pretendo pronunciarme sobre la cucstión debatida acerca de si la leologia es o no es una "ciencia" en

2. Diccionario Teológico, p. 528.

3. Asi ha sido desde el nacimicnlo de la "Icologia pastoral" en la Viena de la cmperaIriz Maria Teresa, en el siglo XVIII. hasti la abundante producción bibliográfica sobre esta malcria, principalmente en lengua alemana. sin olvidar las numerosias publicaciones en castellano, francés e italiano. Cfr. el articulo de F. J. Calvo, cilado en la notia $I$.

4 Sobre este concepto. su historia y su signilicado, cfr. E. Vilanova, "Taología". cn C: Floristín y J. J. Tumayo, Conceptos fundamentales del cristianismo, Madrid (09)3, pp. 1.322-1.325. 
sentido estrictos. Allá los entendidos con esa cuestín, que de momento no me interesa. Lo que quiero dejar claro es que, sea cual sea la opinión que se tenga sobre el estatuto epistemológico de la teologfa, lo que está más claro que la luz es que hablar de teología es hablar de un saber y, por tanto, de una teoría. Esta teoría se ha elaborado a partir del concepto de "revelación", entendida ésla como conjunto de verdades, que se pueden formular - y de hecho se han formulado- en dogmas, o sea, en proposiciones doctrinales sobre las que se han montado nuevas teorfas y especulaciones incontables. Desde lo más antiguos símbolos de la fe hasta los más recientes y completos tratados teologicos, lo que siempre ha estado en juego ha sido una doctrina. Ahora bien, esto quiere decir, por lo pronto, una cosa muy simple: la teología ha brotado fundamentalmente más de los libros que de la vida.

Enseguida voy a indicar las consecuencias que se derivan de este hecho básico. Pero antes quiero aportar otros datos que conviene tener en cuenta. Ante todo, es importante no olvidar que la doctrina sobre la fe (o sea la teología) ha sido elaborada, fuera de contadas excepciones, por "hombres de Iglesia". Esto quiere decir varias cosas. Primero, que la teología ha sido pensada y escrita por varones, ya que la apoitación de las mujeres a la teologfa ha sido, hasta ahora, escasa y reciente6. Segundo, que la teología ha sido pensada y escrita, en una abrumadora mayoría, por varones célibes7. Tercero, que la teologla ha sido pensada y escrita por hombres suficientemente instalados tanto social como económicamente, puesto que históricamente ésa ha sido la situación de los eclesiásti-

5. Sobre esıe asunto, es clásico el estudio de M. D. Chenu, ¿Es ciencia la teología?, Andorra. 1959. Véase tambiên W. Pannenberg, Teoría de la ciencia y Teología, Madrid, 1981.

6. De hecho sólo a partir de los años sesenta del presente siglo se puede decir que las mujeres han empezado a tomar parte. de alguna manera, en el quehacer teológico. Una presentación de este problema, con información bibliográfica, en M. M. Pintos, "Teologfa feminista", en Concepros fundamentales del cristianismo, pp. 1327-1336.

7. Cono es sabido, desde principios (lel siglo IV, el concilio de Elvira impuso, no la ley del celibato (como se suele decir inexactamente), sino la obligación de la continencia: los ordenados in sacris podían estar casados, pero no podían usar del matrimonio (can. 33). A partir del concilio Il de Letrán (año II39) se prohibe a los ordenados (de subdiáconos a obispos) tomar esposa (can. 6). En las iglesias de nriente se permitió el matrimonio a los ordenados, con tal de que se casaran antes de la ordenación (así lo decrel6 el concilio Quinisexto o Trullano, del año 692, en el can. 61. C.r. J. M. Castillo. Para comprender los ministerios de la Iglesia, Estella, 1993, pp. 79-90. Por tanto, s6́lo en los primeros siglos y, más tarde, sólo en oriente. puido haber teólogos casados. $\mathrm{Y}$ los hubo, en algunos casos. Pero fueron los menos, dadu gue la nıayor parte de los grandes autores antiguos fueron obispos o monjes. Al decir todo esto. no me reficro, por supucsto. a los tcólogos de las iglesias nacidas de la reforma. a partir del siglo XVI. 
cos, tanto seculares como religiosos. Es más, durante siglos, los teólogos han sido considerados como "notables" en la sociedad. Cuarto, que la teología ha sido pensada y escrita, no por los laicos, sino por clérigos". Lo cual significa, entre otras cosas, que la teología ha sido un saber "controlado" por la autoridad eclesiástica; y eso, en última instancia, quiere decir que ha sido (y sigue siendo) un saber sometido a un condicionante extracientífico9.

Ahora bien, todo esto está diciendo claramente que sectores importantes, muy importantes, de la vida han quedado al margen de la elaboración de la teología: las mujeres, los casados, los seglares, los más amplios sectores del pueblo. O sea, casi todo el mundo. Sólo un grupo muy minoritario y muy condicionado, social e ideológicamente, ha sido el agente y el responsable del saber teológico. Por lo tanto, no se trata sólo de que la teología ha brotado fundamentalmente más de los libros que de la vida, sino, además de eso (y sobre todo),

8. La aportación de los laicos a la teologla ha sido escastsima. En los tres primeros siglos hubo teólogos laicos importantes. Baste recordar a Tertuliano y a Orígenes. Pero son excepciones. Incluso de Origenes sabemos que fue ordenado presbítero en Palestina. Cfr. M. Jourjon, "A propos du 'Dossier d'ordination' d'Origène". Mélanges de Science religieuse 15 (1958) pp. 45-58. También hay que recordar la aportación laical a la teologla en el siglo XIX, sobre todo en Francia. Son conocidos los nombres de Chateaubriand, Ballanche, J. de Maistre, Madame de Stael; en España, Donoso Cortés, elc. Pero sabemos que todo este movimiento estuvo determinado por la reacción ultramontana contra la revolución francesa y sus concecuencias. $C f r$. Y. Congar, L'ecclesiologie, de la Révolution francaise au concile du Vatican, sous le signe de l'affirmation de l'autorité, en L'ecclesiologie au XIX siecle, París, 1960. pp. 77-114. De manera mós general, ha estudiado este fenomeno y estos autores $\mathbf{E}$. Vilanova, Historia de la teologia cristiana, vol. III, Barcelona, 1992, pp. 494-501.

9. Hago notar que no digo anti-cientííco. sino extra-cientifico, en cuanto que la inslancia autoritaliva, por su estructura misma, no dimana directamente de la dinámica del saber, sino de la dinámica del poder. Pero al mismo tiempo que digo esto, afirmo y deliendo (como tiene que hacer todo católico) que la autoridad magisterial en la Iglesia tiene el derecho y el deber "de interpretar auténticamente la palabra de Dios. escrita o transmitida", según la afirmación del concilio Vaticano II (DV 10, 2). En esle sentido, el magisterio eclesiático puede y debe intervenir para garantizar la ortodoxia de la enseñanza en la Iglesia, cuando lo crea conveniente. Lo que ocurre (y esto también hay que recordarlo, por una elemental honestidad cientifica) es que, históricamente y de hecho, la autoridad y el magisterio ordinario de la lglesia se han equivocado suficientes veces. Y se han equivocado, además, en asuntos de importancia y en los que hoy parecen muy evidentes las posturas contrarias Esto esá sobradamente demostrado con casos y datos incontestables, como to ha probado recientcmente el profesor J. I. González Faus, La autoridad de la verdad. Momentos oscuros del magisterio eclesiástico. Facultat de Teologla de Catalunya, Barcelona, 1996. especialmente en pp. 177-183, donde el autor hace el balance de los textos y hechos que aduce. 
que ha brotado de un saber enormemente restringido y condicionado. Un saber en el que la problemática, los intereses y hasta el lenguaje estaban, con bastante frecuencia, ausentes y distantes de la vida que lleva el común de los mortales. A todo lo cual hay que añadir todavía un dato decisivo: Ja teología, que de facto se ha impuesto y se ha exportado al mundo entero, ha sido un pensamiento eurocéntrico. Es decir, ha sido y sigue siendo, en gran medida, el pensamiento de una cultura deterninada. Una cultura dominante y prepotente, que, en consecuencia, desde la dominación y la prepotencia ha pasado y ha diclado lo que los demás habitantes del planeta tenían que pensar y practicar, si es que aspiraban a escapar de la eterna perdición. Si a todo esto sumamos los inevitables (y muchas veces inconscientes) intereses sociales, económicos y desde luego políticos, que históricamente han condicionado la elaboración del saber teológico, entonces hay derecho para preguntarse: ¿hasta qué punto y en qué medida, la teologia, que de hecho existe (la más abundante y la más extendida), es la reflexión sobre la fe de la Iglesia? Que es la reflexión sobre el saber y las convicciones de los clérigos, de eso no hay duda. Pero vuelvo a preguntar: ¿es eso s6lo la fe de la Iglesia? Más aún, ¿es eso toda la fe de la Iglesia? Estas preguntas se le ocurren a cualquiera, después de lo que he dicho antes. Sobre todo, si tenemos en cuenta que la Iglesia es la toralidad de los creyentes. Y si además pensamos (lo cual es más importante) que la fe cristiana no se puede entender desligada de la vida.

Al llegar a este punto, me parece que estamos tocando el nudo de la cuestión. Que la fe comporta unas determinadas convicciones (libres) y, en ese sentido, conlleva un determinado saber, es cosa que los creyentes no podemos poner en duda 10. Pero, al mismo tiempo que decimos eso, afirmamos que, en la fe, más fundamental que el saber es el vivir. La leologla del Nuevo Testamento llama fe muerta (o sea que no es fe) a la convicción o al saber que se desliga de la forma de vivir, exactamente de la forma de vivir que toma en serio el sufrimiento de los pobres (Sant 2, 14-17.24-26). Y el evangelio de Juan, cuando los discípulos llevaban sólo cuatro días ( $c f r$. Jn 2, 1) conviviendo con Jesús, dice que aquellos hombres "creyeron más en él" (Jn 2, 11). O sea, ya creían desde el primer momento en que se pusieron a vivir con Jesús. ¿Qué sabían sobre la fe aquellos humildes hombres del pueblo cuando empezaron la nueva forma de

10. La fe no se reduce a un acto intelectual, ya que es la respuesta "por la que el hombre libremente se entrega todo a Dios", según la formulación del concilio Vaticano ll (DV 5). Pero el mismo concilio recuerda la enseñanza del Vaticano l: "rindiendo al Dios revelante el pleno acatamiento de su entendimiento y voluntad" (DS 3008). En este sentido, la fe es también una virtud intelectual. Fe que se adhiere, ciertamente, a la verdad que es Dios, pero también a las palabras humanas de la Escritura, a las rormulas dogmáticas, aparentemente materiales, que cumplen una función de signo a Iravés del cual se nos propone la verdad. Cfr. E. Vilanova, "Fe", en Conceptos fundamentales del cristianismo, pp. 502-503. 
vida? Nada. Y sin embargo, ya tenían fe. Decididamente, la fe cristiana, por más que alcance su perfección en un determinado saber, es fundamentalmente (y anles que nada) una forma de vivir. Por eso, sin duda, hace más de treinta años, el profesor Juan Alfaro concluía con estas palabras su exhauslivo esludio acerca de la fe en la terminologia de la Biblia: "El presente análisis de loda la terminología biblica muestra que la noción de la fe es fundamentalmente idéntica en el Anliguo y en el Nuevo Testamento: 'creer' incluye la adhesión integral del hombre a Dios que se le revela y le salva"lI. Ahora bien, hablar de "adhesión integral" es obviamente hablar, no sólo ni principalmente de un saber, sino, antes que eso y sobre todo, de una forma de vivir. Es la vida entera de la persona, que se entrega, se orienta y se organiza en función del designio de Dios.

Esta compresión fundamental de la fe es determinante para entender correctamente en qué debe consistir la respuesta del hombre a Dios, que se revela, se acerca y se entrega a la humanidad. Hoy sabemos perfectamente que, cuando ocurrió esta revelación, lo primero que hubo no fue ni doctrinas, ni teorías, ni libros. Lo primero que hubo fue la historia, la vida de un pueblo. Los libros y las teorías vinieron mucho más tarde, siglos después. Y vinieron de tal manera que cuando hablan de la fe, la presentan como el momento a partir del cual el pueblo emprende una nueva vida. Tal es el sentido de Exodo 14, 31 y 19, 9 en relación al relato fundamental de Exodo 3, 1-2212. Por eso, los especialistas en Biblia insisten en que la fe incluye esencialmente "fiarse" de Dios y "obedecer" a Dios 13. Pero, es claro que estas dos cosas comportan necesariamente una forma de vivir. Que es, en definitiva, to que he dicho anles de la fe, según el evangelio de Juan 14.

Ahora, pienso yo, se puede comprender en qué consisle la sorprendente originalidad de la leología que han aporlado y aportan las comunidades eclesiales

11. J: Alfaro, "Fides in terminologia biblica", Gregorianum 42 (1961) p. 504.

12. Es importante tener presente que en este texto se narra la aparición de Dios a Moisés para comunicarle su proyecto de que el pucblo cambie de vida, saliendo de una vida de esclavitúd para adquirir una vida libre; Lo que está en juego es un proyecto de vida. Y el pucblo tiene que aceptarlo por medio de la fe (Ex 4, 1.5.8.9). Un detaltado análisis de la terminología. en el arliculo de J. Alfaro, citado en la nota I1, pp. 466467.

13. Cfr. J. Alfaro, op. cit., p. 474; A. Weiscr, TWNT VI, pp.191-146: J. van der Ploeg, "L’Esperance dans l'Ancien Testament", Revisia Biblica 61 (1954) pp. 480-507.

14. Los cspecialistas en la teología de san Juan hacen notar que, cuando el verbo pistcúcin (creer) se consiruye con dativo, expresa la persona a la que se adhiere uno por la fe. Esta persona sólo en dos cassos es Dios (Jn 5, 24; IJn 5, 10); en los demás lextos, es Jesús (Jn 4, 21; 5, 38.46; 6, 30; 8, 31.45.46; 10, 37.38; 14, 11). Por lo tanto, la fe comporta esencialmente una relación personal con Cristo. Ahora bien, la adhesión a una persona y la relación estable con ella se expresan en la vida o, más exactamente, en la forma de vivir. 
de base. Si la teología es la reflexión sobre la fe, eso quiere decir que la leología es, antes que nada, reflexión sobre la vida. Más exactamente, reflexión sobre aquella forma de vivir que toma en serio el evangelio. Por lo tanto, es una vida pensada y asumida conscientemente. Porque en ella es mucho lo que se juegan $y$, de hecho, se han jugado las personas y los grupos que pertenecen a las comunidades de base. Muchas de eslas pcrsonas (y comunidades enteras) han sido perseguidas, expulsadas de sus casas, de sus pueblos y de su patria, obligadas a vivir en la clandestinidad o como refugiados $y$, por supuesto, cientos de estos hombres y mujeres han sido asesinados impunemente. La historia de los últimos treinta años en América Latina está marcada a sangre y fuego por este hecho. Y lo más importante, para lo que aquí vengo diciendo, es que estas gentes han sufrido la persecución, y hasta han dado su vida, por el hecho de pertenecer a las comunidades eclesiales de base. Ahora bien, habría que estar ciegos para no darse cuenta que una forma de vivir que acarrea esas terribles consecuencias, licne que ser forzosamente una vida pensada y asumida conscientemente.

Este hecho constiluye el dato al que yo quería llegar. Porque eso significa dos cosas. Primero, que una forma de vivir, que llega hasta esos límites, es en sí misma fe: le en Dios, fe en Jesucristo, le cristiana llevada hasla sus últimas consecuencias. Segundo, que esa fe, pensada y asumida conscientemente, es, en si misma, teologia: teología en el sentido más propio de la palabra, puesto que, como se ha dicho tantas veces, la teología no es sino la reflexión sobre la fe.

Seguramente en esto consiste la uportación más original que las comunidades de base han hecho a la Iglesia. Porque ellas han llevado a efecto un nuevo modo de hacer leología: una teología que brota de la vida. O más exactamente, una tcología que brola de una forma de vivir. En este sentido, quiero hacer nolar algo que me parcce determinante en lodo este asunto: a mi manera de ver, no se Irata de que las comunidades de base han sido fruto y resultado de la leologia de la liberación, sino exactamente al revés: ha sido la teología de la liberación la que ha brotado, como reflexión técnicamente elaborada, del hecho teológico y de la teología que son en sí las comunidades de base. Y esto explica, sin duda alguna, lo sorprendente y hasta lo inquietante que ha resultado toda esta teología: la más básica y primera, la que han hecho con su vida las comunidades de base; y la más técnicamente elaborada, la que han escrilo los teólogos de oficio, la Ilamada "teología de la liberación". Los que se empeñan en seguir diciendo que lo inquietante de esta leologia es que se ha inspirado en el marxismo, o no saben lo que dicen o hablan con mala fe. Porque la pura verdad, el hecho que nadie puede negar, es que la teología primaria y fundamental, la que ha hecho posible la "leología de la liberación", es la teología que ha brolado, no de los libros ni de las leorías, sino de la vida misma o, más exaclamente, de la forma de vivir que han asumido y llevan adelantc las comunidades eclesiales de base. 
Por eso, la teología de la liberación nos ha parecido una cosa tan nueva. Y para algunos, tan peligrosa. En los ámbitos eclesiásticos, estábamos acostumbrados a montar teorías sobre teorías, desde el platonismo de los padres hasta el aristotelismo de los escolásticos; más aún, hasta los conatos más recientes de "bautizar" las interpelaciones de la ilustración. A fin de cuentas, de una manera o de otra, especulación sobre especulación. Y quiero dejar bien claro que la especulación es necesaria, más aún absolutamente imprescindible. Pero lo mismo que digo eso, insisto en que moverse siempre en el plano alzado de las leorías y de la especulación enıraña un riesgo, que puede resulıar muy peligroso, a saber: olvidarse de lo más obvio, ausentarse de la vida y, sobre todo, olvidarse del sufrimiento de los que peor lo pasan en este mundo. Para nadie es un secreto que la especulación y la abstracción han sido una trampa, en la que han caído muchos té́logos y no pocas teologías. De manera que, en realidad, el mayor beneficio que nos han hecho y nos están haciendo las comunidades de base, es recordarnos una cosa tan elemental como decisiva: que la teología tiene que brotar, antes que nada, de la fe. Y que la fe, antes que nada, es la vida: exactamente la forma de vivir, que por lidelidad al Dios de Jesús (que es inseparable de la fidelidad al hombre), es capaz de renunciar a la vida misma. Esto no es una teoría. Esto es un hecho, que ha ocurrido y sigue ocurriendo. Y pienso que este hecho, conscientemente asumido y tantas veces inevitablemente reflexionado por los que lo han sufrido en carne propia, es verdadera teología, quiza la primera y la más necesaria teologíals.

15. Al decir esto, soy consiente de que alimno algo que, para muchos, puede resultar tan nuevo como inaceptable. Los teólogos de la liberación, desde Gustavo Gutiérrez, han entendido la teología "como reflexión crítica desde la praxis" (Teología de la liberación, Lima, 1971, p. 20). Aquf parece que yo adelanto el concepto de teología a la praxis misma y a la praxis sola. En realidad, no es asf. Lo que digo es que la vida misma, la vida de fe que han asumido y llevan adelante las comunidades, es una realidad tan densa y tan comprometida (incluso tan arriesgada), que en sí misma exige ser pensada y asumida conscientemente. Ahora bien, eso en sí ya es la teología, es una forma de teología, la teología que brota directamente de la vida. Sin duda, los primeros té́logos de la liberación tuvicron que hacer un esfuerzo titánico para dejar bien claro que su teología era también teologla "cientffica" y "crítica". Por tanto, que no era una teología inferior a las demás teologfas. Hoy, me parece a ml. podemos (y quizá debemos) mirar la cosa con más amplitud. Recientemente, un gran conocedor de la teología y su historia, el profesor Evangelista Vilanova, escribla lo siguiente, recordando a otro gran teólogo, M. D. Chenu: "Los conceptos que utiliza la teologla como reflexión son esenciales a la vida del espíritu, pero no son 'toda' la vida del espíitu. Tenemos que confiar en ellos, pero también tenemos que desconfiar de ellos. Por esta razón, en un tercer estadio, la teología debe situarse continuamente en estado de invención -ya que siempre permanece en anhelo de fe-, reencontrando sin cesar su objeto, vivir en él, bañada en la experiencia cristiana 


\section{Une teología que hacen los pobres}

Las comunidades eclesiales de base, tal como han existido y existen en América Latina, se componen fundamentalemente (y casi siempre exclusivamente) de gente pobre: campesinos, grupos indígenas marginales, habitantes de los más iniserables suburbios en las grandes ciudades, etc. Esto quiere decir obviamente que la teología de las comunidades eclesiales de base es, no sólo una teología que brota de la vida, sino además de eso $-y$ sobre todo-, una leología que brota de una forma determinada de vivir: la vida de los pobres. Ahora bien, en eso reside, me parece a mí, lo más nuevo, y sin duda alguna, lo más inquietante de esta teologia.

Me explico. Muchos creyentes piensan que la cuestión que plantean los pobres a la teología se reduce al problema ético, es decir, la exigencia e incluso la urgencia que se nos impone de cambiar radicalmente el presente orden social, en el que miles de millones de seres humanos se mueren literalmente de hambre $y$ de miseria, mientras una minoría privilegiada despilfarra los bienes y las fuentes de energía del planeta, en un evidente abuso de consumismo16. Por supuesto, el problema ético es gravísimo. Y, desde ese punto de vista, no cabe duda que el

como en una atmósfera fuera de la cual se atrolia". E. Vilanova, "Teologfa", en Conceptos fundamentales del cristianismo, p. 1319, que cita a M. D. Chenu, La fe en la inteligencia, Barcelona, 1966, p. 117. Esta continua "invención, bañada en la experiencia cristiana", también es teología, con el mismo (o quizá con más) derecho que la más alta especulación que pueda hacer el estudioso de turno.

16. Según los datos que aporta el último informe sobre desarrollo humano elaborado por la ONU (y hecho público el 16 de julio de 1996), el 20 por ciento más rico de los habitantes del planeta consume el 85 por ciento de la riqueza mundial. Lo cual quiere decir obviamente que el 80 por ciento de la población mundial se tiene que contentar con el 15 por ciento de los recursos del planeta. Es decir, la dinámica que ha desencadenado el sistema económico imperante (el capitalismo neoliberal) actúa de tal manera que la riqueza del mundo se va concentrado cada día más en menos manos. La brecha entre ricos y pobres aumenta, por días, de manera increßble. $Y$ así resulta, por ejemplo, que, según el citado informe de la ONU, los bienes que poseen las 358 personas más ricas del mundo equivalen al $\mathbf{4 5}$ por ciento de toda la población pobre del planeta, lo que significa que esas 358 familias afortunadas suman más riqueza que los 2,500 millones de personas más pobres del mundo. Inevitablemente, las consecuencias que se siguen de esta situación son aterradoras: 40,000 personas mueren de inanición cada día; 1,000 millones sufren de hambre crónica. Y repito que estas cifras van en aumento, lo que lleva a casos y situaciones increibles. Por ejemplo, hace unas semanas, una religiosa misionera en el Zaire me contaba que, en ese pals africano, un licenciado gana un dolar al mes y con ese dolar, lo único que se puede comprar son seis panes. Y sabemos que peor que Zaire se encuentran parses como Niger, Sierra Leona, Somalia y Mali, por citar algunos ejemplos nada más. Cfr. sobre todo este asunto, relación de El País, 17 de julio de 1996. También en V. Verdú, "El crimen capital", en El País, 15 de agosto de 1996. 
asunto más urgente que debcmos solucionar o por lo menos aminorar, en la medida de nuestras posibilidades, es el hanibre y la miseria de los pobres. Pero cuando se trata de analizar la rclación entre los pobres y la teología, tenemos que empezar reconociendo que la cucsión más profunda que los pobres plantean al quehacer teológico es el problema hermenéutico.

Todos sabemos que el quehacer propio de los teólogos de oficio suele empezar por analizar las enseñanzas de la Biblia. la doctrina del magisterio eclesiástico y las lecciones que aporta la tradición cristiana. Todo esto es lo que constituyc el punlo de partida del mélodo leológico eslablecido. Y, en general, se tiene la impresión de que las cosas lienen que ser asi, de manera que eso no ofrece más problema. Y sin embargo, es problema más profundo de to que algunos imaginan. Porque antes de emprender el análisis de la Biblia, del magisterio y de la tradición, hay que preguntarse desde dónde intentamos hacer ese análisis. Y, por lo tanto, desde dónde pretendemos enterarnos de lo que la Biblia, el magisterio y la tradición nos enseñan acerca de Dios, de Cristo, de la Iglesia y de todo lo que estudia la teología. Digo esto porque, con frecuencia, tengo la impresión de que muchos teólogos no han caído ni caen en la cuenta de que todo acceso a la realidad y, por lo tanto, toda leclura de la realidad es, al mismo tiempo e inevitablemente, una interpretación de dicha realidad. Al decir eslo, como es bien sabido, no estoy sino enunciando el principio más elemental de la hermenéulica 17. Por otra parte, aquí es decisivo tener presente que cuando la realidad, a la que pretendemos acceder, es una realidad transcendente, entonces, el peligro de una interpretación subjeliva es mucho mayor. Porque to Iranscendente es to que, por definición, se sitúa más allá de los límites de nuestro campo inmanente de objclivación. De donde resulta que todo acceso a Dios y su revelación es, de manera inevilablc, una leclura "mediada" y, por lo tanto, "filtrada" por los condicionamientos que determinan, modifican y a veces pervierten nuestro encuentro, nuestro conocimiento y nuestra lectura de esa realidad última, que nos rebasa, nos supcra y de la cual no podemos tener evidencia alguna.

Entre los 'condicionamientos que, como he dicho, determinan, modifican y hasta posiblemenle pervierten nuestro acceso a Dios, el más decisivo es, sin duda alguna, el lugar desde dónde cada uno intenta conocer a Dios y relacionarse con El. Aquí resulta obvio adverlir que, cuando hablo de "lugar", no me refiero a lugar geográfico, sino a lugar epistémico, es decir, a la situación y al conjunto de circunstancias que, de una manera o de otra, influyen en el conoci-

17. Para una introdución a la hermenćulica y su hisloria, cfr. F. von Mussner, Geschichte der Hermeneutik von Schleicrmacher bis zum Gegenwart, en Handbuch der Dogmengeschichte, Freiburg, 1970, pp. 3-34. La perspectiva tcológica está suficientemente indicada en J. L. Segundo, "Lal opción por los pobres como clave hermenéulica para entender el evangelio". Sol Terrae 6 (1986) pp. 473- 482. 
miento, lo filtran, y sin que el sujeto se dé cuenta de ello, interpretan la realidad, seleccionando y destacando datos de esa realidad $y$, al mismo tiempo, marginando o deformando otras dimensiones de la misma realidad, que son fundamentales e incluso decisivas.

Por otra parte, aquí es importante recordar que de este proceso nadie se escapa. Todos y siempre, al intentar acceder al Transcendente, inevitablemente lo interpretamos, lo tiltramos y corremos el peligro de deformarlo. Si esto es así, el problema está en determinar desde dónde podemos, con menos peligro de deformación, intentar acercarnos a Dios y su revelación. O dicho de otra manera, se trata de precisar el lugar desde el cual podemos, con más garantías de objetividad, comprender a Dios y lo que El nos ha querido transmitir.

Esto supuesto, los cristianos sabemos que Jesús, el Mesías, es la imagen visible de Dios invisible (cfr. Col 1, 15). Es decir, Jesús es quien mejor ha conocido a Dios y quien mejor y más exactamente lo ha dado a conocer ( $c f r$. Jn, 1,18 ), hasta el punto de que, según el mismo Jesús, quien lo ve a él, por eso mismo, está viendo al Padre (Jn 14, 9). Aqư es importante destacar que no se trata, ni sólo ni principalmente, de un asunto de doctrinas o teorías sobre Dios, sino de algo mucho más amplio y más cercano a todos los mortales: la expresividad de la persona y la vida entera de Jesús, lo que en él se veía (como le dice a Felipe), lo que se metía por los ojos, lo que "palparon" las manos y "contemplaron" quienes lo vieron (1Jn I, 1), o sea, no sólo sus palabras, sino además sus costumbres, su estilo de vivir, sus preferencias, lo más sensible y lo más inmediato, todo eso es lo que reveló a Dios y su proyecto. Es decir, todo eso (además de sus enseñanzas) es lo que nos ha dado a conocer quién es Dios, cómo es Dios y lo que Dios quiere y espera de nosotros.

Ahora bien, ¿desde dónde realizó Jesús esta tarea y cumplió esta misión? De Jesús se dice que nació en un establo, donde viven las bestias y que murió colgado en una cruz, donde morían, en aquel tiempo, los criminales más peligrosos y los subversivos del orden establecido. Es evidente que un individuo, que empieza y acaba así, es un hombre descolocado, marginado del sistema, no integrado en el conjunto de valores, instituciones y principios que configuran el "normal" funcionamiento de una sociedad. Es decir, Jesús se situó en la marginalidad del sistema. $Y$ desde ahí comprendió comectamente a Dios y reveló correctamente a Dios. Aquí y en esto reside el sentido profundo de la solidaridad de Jesús con los pobres y con los pecadores, con los leprosos y los samarilanos, con los miserables y vagabundos de los caminos (cfr. Mt 22, 9-10). Como reside igualmente el significado último del conniclo y el enfrentamiento de Jesús con los sacerdotes, senadores y letrados, con los fariseos y observantes, y también con los ricos de su tiempo. Todo esto ha sido estudiado hasta la saciedad, ha sido analizado hasta el último detalle, de manera que yo no voy a repetir lo que otros han investigado con más competencia y han explicado con más 
autoridad 18 .

Eso sí, lo que me interesa dejar aquí bien claro es que los pobres son no sólo el lugar social, sino sobre todo el lugar epistémico desde el que, con más garanlías de objetividad, podemos entender a Dios, los proyectos de Dios, la voluntad de Dios. Aquí resulta decisivo recordar la afirmación de Jesús: "Bendito seas, Padre, Señor de cielo y tierra, porque, si has escondido estas cosas a los sabios y entendidos, se las has revelado a la gente sencilla" (Mt 11, 25). La expresión "gente sencilla" traduce el têrmino griego népios, que literalmente (né-épos) significa "el que no tiene habla", lo que en latín dirfamos in-fans (Zerwick, Analysis Philologica N. T. G., 28), o sea, el niño. Esta palabra, contrapuesta a los "sabios" y entendidos", se refiere claramente a los que no tienen nada que decir en la sociedad, los que no pintan ni representan nada; en otras palabras, la gente sin importancia. Ahora bien, esta gente, en la sociedad de todos los tiempos, es la gente pobre, que carece de la cultura de los sabios y entendidos, los que constituyen los estratos influyentes en el tejido social.

Pues bien, según Jesús, desde la situación de esta gente es desde dónde se comprende a Dios y las cosas de Dios. Por eso, sin duda, cuando san Pablo explica en quiénes se manifiesta la "sabidurfa de Dios", afirma provocativamente que ésos no son ni los "intelectuales", ni los "poderosos", ni la "gente de buena familia" (ICor 1, 26). Y añade el mismo Pablo: "todo lo contrario: lo necio del mundo se lo escogió Dios para humillar a los sabios; y lo débil del mundo se lo escogió Dios para humillar a lo fuerte; y lo plebeyo del mundo, lo despreciado, se lo escogio Dios"' (1Cor 1, 27-28). Sean cuales sean los matices exegéticos que haya que hacer para comprender el significado de este texto impresionante 19, es claro que en él se trata no sólo de la sabidurfa de Dios hacia

18. Se puede encontrar una información bibliografica abundante en E. Schillebeeckx, Jesús. La historia de un viviente, Madrid, 1981, pp.128-162; J. Moltmann, Der Weg Jesu Chiristi, München, 1989, pp. 117-124; J. I. González Faus, La humanidad nueva, Vol. I, Madrid, 1974, pp. 87-114; X. Pikaza, El evangelio. Vida y pascua de Jesís, Salamanca 1990, pp. 63-117; J. Sobrino, Jesucristo liberador, San Salvador 1994, pp. 87-133. Sobre este asunto, resulta sugerente el título de la obra de J. P. Meier, A Marginal Jew, New York, 1991, 2 vol. Como tambiên es estimulante el sugerente estudio de A. Holl, Jesus in schlechter Gesellschaft. Stuttgart, 1971, o sea, Jesús y las malas compañías, un análisis del medio social y cultural en el que se situó.

19. Es verdad que Pablo se refiere en este texto a su doctrina fundamental, según la cual, el llamamiento a la fe se debe a la bondad misericordiosa de Dios y no a las obras del hombre (cfr. R. Kugelman, "Primera carta a los corintios", en Comentario biblico 'San Jerónimo', t. IV, 2, 17). Pero es evidente que esta tesis teológica no margina ni quita fuerza a la afirmación, igualmente teológica, según la cual el saber y el comprender el misterio y el designio de Dios se encuentran en "lo necio", "lo débil", "lo plebeyo", no precisamente en los poderosos, instalados y ricos de este mundo. 
los hombres, sino además y conjuntamente del saber y entender de los hombres en cuanto se refiere al misterio desconcertante de Dios y al designio salvador de Dios20. Ahora bien, Pablo afirma categoricamente que ese saber y entender sobre Dios se encuentra precisamente en lo marginal de este mundo o, dicho de otra manera, en la marginalidad del sistema establecido. Es, por lo tanto, desde lo marginal del orden presente desde donde podemos, con más garantías de objetividad, conocer a Dios. Y eso significa, ni más ni menos, que desde la marginalidad de los pobres es desde donde mejor y más correclamente se puede hacer teología. Aquí cstá el secreto, me parece a mí, de la calidad y la importancia de la teología que han hecho y están haciendo las comunidades eclesiales de base.

Pero es claro que aqul surge una pregunta inevilable: ¿por qué precisamente desde la marginalidad del sistema es desde donde mejor podemos conocer a Dios? Para responder a esta pregunta, hay que empezar recordando un principio básico en epistemología: la relación entre conocimiento e interés 21 . El lugar que uno ocupa en la sociedad y en cl sistema genera incvitablemente intereses, las más de las veces ocultos para el que los liene. Unos intereses determinados producen un conocimiento determinado. En este sentido, los intereses que se derivan de la acción y de la experiencia que vive el sujeto, filturan su acceso a la realidad y condicionan radicalmente la compresión, la valoración y la interpretación que el mismo sujeto hace al conocer, valorar y enjuiciar. Esto significa, en última instancia, que el lugar social que cada uno ocupa en el sistema establecido, determina decisivamente el lugar epistémico, a partir del cual interpreta y valora la realidad. He aquí la primera razón en virtud de la cual se comprende por qué el hombre Jesús de Nazaret, desde la solidaridad con los pobres, es decir, desde la marginalidad del sistema, comprendió al Padre del cielo como nadie lo ha comprendido y fue, de esa manera, la revelación de Dios e incluso la imagen visible y palpable (cfr. IJn 1, 1) de Dios invisible.

20. A eso se reliere expresamente Pablo en los vv. 21-24, concretamente cuando alirma que la sabiduría de Dios no fue reconocida por el mundo, que luvo esa sabiduría por locura. Por lo tanto. Pablo no habla sólo del saber de Dios, sino igualmente del entender de los hombres.

21. Es clásico y bien conocido el estudio de J. Habermas, Conocimiento e Imterés, Madrid, 1989. Como es sabido, Habermas lleva su análisis hasıa el extremo de afirmar que la teoría de la ciencia sólo es ya posible como teoría (crílica) de la sociedad. Pero debo advertir que cuando Habermas habla de "interes" no se refiere a intereses materiales, sino a to que él llama "intereses rectores del conocimiento", en cuanto que "la sintaxis referencial del lenguaje en que se formula el saber leórico permanece reconectada a la lógica del correspondienle contexlo precientífico de experiencia y acción" (op. cil., p. 323). Se trata, en clefinitiva, de los intereses que "protegen, frente al discurso, la unidad del sistema de acción y de experiencia" (op. cir., p. 324). 
Pero hay una segunda razón que va más al fondo de las cosas. En el asunto, que venimos analizando, no se trata de conocer cualquier cosa, sino que se trata precisamente de conocer a Dios y todo lo referido a El. Por lo tanto, la cuestión central está en que se trata de un conocimiento religioso. Ahora bien, la sociología de la religión nos viene enseñando, desde Max Weber, que las religiones han sido y siguen siendo una sacralización de la realidad: sacralización del sistema, sacralización del poder, sacralización del derecho, sacralización de las instiluciones, sacralización de los valores vigentes y de las situaciones establecidas, sacralización de las personas y de las cosas 22 .

De esta manera, la religión otorga un estatuto de absolutez a lo que en sí es contingente y no pasa de ser producto humano, incluso consecuencia de la pecaminosidad humana. $Y$ así resulta que el poder viene de Dios, y hay que someterse a él por voluntad de Dios; que el derecho es expresión del orden querido por Dios, incluido el derecho de propiedad y, por lo tanto, la riqueza, que con Trecuencia es presentada como una bendición de Dios; que las dignidades $y$ ascensos se premian con cruces y títulos que remiten a una ultimidad donde, en definitiva, se sitúa Dios. Lo bueno y lo inalo, el orden establecido, en últiına instancia, el sistema es, para el hono religiosus, expresión de Dios, manifestación de Dios, reflejo del crden absoluto y último.

A partir de este planteamiento, con frecuencia inconscientemente asumido, es como el teólogo de oficio suele elaborar su comprensión de Dios y sus explicaciones sobre todo jo que se refiere a Dios. De donde resulta inevilablemente un Dios filtrado por el sistema y, en última instancia, acomodado al sistema. Lo cual quiere decir que no conocemos e interpretamos al sistema desde Dios, sino exactamente al revés: conocemos e interpretamos a Dios desde el sistema, o sea, desde los intereses del sistema y desde las conveniencias del sistema.

Ahora se comprende por qué sólo desde la marginalidad del sistema es como mejor se puede captar, asimilar y vivir lo que representa Dios y todo lo relacionado con El. En otras palabras, sólo desde los pobres o, más exaciamente, desde la situación epistémica que comportan los pobres es desde dónde, con más garantías de objètividad, podemos tener los ojos limpios, que ven la verdadera imagen de Dios. En este sentido y a partir de este planteamiento, se comprende lo que acertadamente ha dicho Jon Sobrino: el inundo de los pobres es una realidad que da que pensar; es una realidad que capacita a pensar y es una realidad que enseña a pensar ${ }^{23}$. Por supuesto, y sobre todo, a pensar en Dios. Precisamente -insisto en ello- porque es un pensamiento que se elabora desde la marginalidad del sistema. Y por cierto, desde la marginalidad, no sólo en el

22. M. Weber. Econonía y sociedad, México. 1969, vol. I. pp. 452-453; 475-477, elc.

23. J. Sobrino, Jesucristo liberador, pp. 44-48. 
plano de la política, la economía y las instiluciones en general, sino, sobre todo, a un nivel más profundo: el nivel del pretendido "consenso universal" (Apel, Habermas), el consenso de la conciencia ilustrada, "justificado por argumentación, fácticamente irrefutable y no superable", que generaría una evidencia "desde la cual se puede postular con sentido una determinada norma de acción"24. En este sentido, y visto a este nivel de profundidad, el pobre, el oprimido (en lo cultural tanto como en lo económico) es el que, según la acertada formulación de Juan A. Estrada, "no puede articular su disenso ni fundamentarlo argumentativamente respecto al consenso ilustrado de los sujetos hegemónicos. La marginación le incapacita para apelar racional-argumentativamente y participar en el consenso ilustrado"2s. He aquí, por lo tanto, la marginalidad del sistema en su dimensión más honda. Porque es marginación, no sólo social y económica, sino además, y sobre todo, marginación epistémica respecto al consenso común, que configura el sistema en que vivimos, pensamos y acluamos.

Por eso, la teología que surge a partir de la experiencia y la conciencia de los pobres, es una teología sorprendente y subversiva para quienes viven integrados en el sistema y, desde el sisterna, están acostumbrados a pensar en Dios y a interpretar a Dios. Porque el Dios del sistema es el Dios que se define a partir del poder (un poder sin límiles), que legitima y justifica el orden (el "orden establecido") y que es enconirado y experimentado en la fascinación que produce lo sagrado (o sea, lo "separado" y puesto aparte del resto de la vida). Ahora bien, el Dios de los pobres es el Dios que se define a partir de la solidaridad con el débil y oprimido, que subvierte las situaciones establecidas y que es enconIrado y experimendado, ante todo, en el espesor de la vida, o sea, alli donde hay justicia, honradez y libertad. De donde resulta inevitablemente una teología inquietante. Porque, en úllima inslancia, es una teología que le quila sus bases al sistema. Y pone el dedo en la llaga, o sea, en cosas que el sistema tiene por intocables e indiscutibles. Por eso, según cuentan los evangelios, la presencia, la actuación y la predicación de Jesús resultaron una cosa tan sorprendente y subversiva. Sencillamente, aquello rompió los esquemas más seguros y más básicos. Y eso explica por qué unos lo luvieron por loco (cfr. Mc 3, 21), otros dijeron que era un demonio ( $c f r$. Lc 11,15 ), los observantes lo acusaron de blasfemo (cfr. Mc 2, 7), los poderosos de malhechor (cfr. Jn 18, 30) y las máximas auloridades vieron en él la amenaza más directa para lodo su montaje religioso-político (cfr. In 11,48 ). Sin duda alguna, la explicación de tanta agitación y lanto alboroto es muy simple: Jesús vio las cosas desde la marginalidad del sistema. Y por eso, las vio de una manera enteramente distinla: su Dios no

24 Juan A. Estrada, "Tradiciones religiosas y élica discursiva", en D. Blanco, J. A. Pércz Tapias y 1. Sáez Rueda (ed.), Discur.so y realidad. En debate con K. O. Apel. Madrid, 1994, p. 187.

25 lbid., p. 203. 
era el Dios del poder y de los poderosos, su ética no cuadraba con el orden establecido, y su religión no encajaba con los esquemas del templo, de los legalismos y los rituales que anteponían lo sagrado al bien del hombre. En el fondo, era y es la teología que surge de la marginalidad. En dos palabras: la teología de los pobres.

Y en esto reside, me parece a mí, lo más imporante, lo más nuevo y hasta lo más inquietante (para muchos) que han aportado y están aportando las comunidades eclesiales de base con su teología. Primero, porque se trata de una manera nueva (y para algunos sorprendente) de ver a Dios y entender a Dios. Segundo, porque se trata de una manera distinta de leer el evangelio. Tercero, porque todo esto quiere decir que el modo de hacer teología o, si se qujere, el método teológico tiene que empezar por algo que es previo a la tradición, al magisterio y a la misma Escritura: a saber, aclararnos sobre el Jugar espitémico desde el cual intentamos comprender la tradición, el magisterio y la Escritura; y ese lugar epistémico no puede ser otro que la solidaridad con los pobres. Cuarto (y esto es lo más decisivo), porque cuando la vida se ve de esta manera, el sisterna establecido y legitimado. desde la religión, el poder y hasta el pensamiento ilustrado, se pone radicalmente en cuestión, es decir, el "orden" se ve como desorden radical. Y entonces (sólo entonces), cuando las cosas se ven así, se hace posible y efectiva la esperanza en un mundo más humano, una snciedad distinta (lo inquietante para muchos), una Iglesia diferente (la Iglesia que Jesús quiso), en definiliva, la utopía.

\section{Una teología que es utopía}

He terminado, hace un momento, hablando de utopía. $Y$ eso es lo que nos queda por explicar. Por supuesto, no voy a repetir aquí (ni sun siquiera resumir) lo mucho que se ha escrito acerca de la utopia26. Lo doy por sabido, ya que este asunto constituye un capítulo importante del pensamiento filosófico, politico y cultural de los últimos tiempos. De todas maneras, me parece conveniente recordar algunas cosas, que son importantes para lo que después voy a decir.

26 Un buen resumen del concepto, con su historia más básica, en J. A. Gimbernat, "Utopía", en Conceptos fundamentales de pastoral, pp. 1015-1022. Trabajos fundamentales sobre el tema: A. Neusüs, Utopie, BerlIn, 1968 (existe traducción parcial al castellano, ed. Barral, Barcelona 1971); K. Mannheim. Ideología y usopía, Madrid 1966; E. Bloch, El principio esperanza, 3 vol., Madrid, 1977-1980; Id., Thomas Münzer. Teólogo de la revolución, Madrid, 1968; J. A. Gimbernat, Emst Bloch, utopia y esperanza, Madrid, 1983; H. Küng, ¿Existe Dios?, Madrid, 1981, pp. 656675. Como obras leológicas, que se relacionan con el pensamiento utópico. es fundamental consultar J. Moltmann, Teología de la esperanza, Salamanca, 1969; J. B. Metz, La fe en la historia y en la sociedad. Esbozo de una teología política fundamental para nuestro tiempo, Madrid, 1979. 
Como es hicn sabido. el pensamiento utópico ha sido una constante del pensamiento humano. Así ha sido, por lo menos, desde la República de Platón, hasta los recientes escritos de Ernsı Blocl. A cualquiera se le ocurre perisar que esta persistencia de lo ulópico a lo largo de la historia, a pesar de la oposición casi constante que ha encontrado, nos está indicando, con bastante evidencia, que entre los hombres y mujeres de este mundo ha habido, y sigue habiendo, un anhelo incontenible, una aspiración profunda, que busca una sociedad distinta, que se afana por el logro de csc ideal cle convivencia, que es esperanza en el futuro $\mathrm{y}$, a la vez, rechazo de la resignación malsana y negativa que acepta el sufrimiento como algo incvitable.

Por otra parte. hoy está más que demostrado que la oposición a la utopía ha venido siempre de parte del pensamiento conservador. En esto están de acuerdo prácticamente todos los estudiosos del tema27. Lo cual es comprensible. Porque si la utopía significa cambio, renovación profunda y radical, y, por lo tanto, crítica igualmente radical de lo establecido, es lógico que el pensamiento conservador se ponga de uñas ante semejante planteamiento. Conservadores suelen ser aqucllos a quienes les va bien con cl sistema vigente. Mientras que, por el contrario. los marginados sociales, los excluidos económica, política o culturalmente, si no están "domesticados" por el sisterna, forman la masa de los disconformes y, por eso, los renovadores e incluso los revolucionarios. Estas gentes son, de hecho, el caldo de cultivo $\mathrm{cn}$ cl que nace, crecen y maduran las mejores utopías.

Por eso se comprende que el medio social, político y cultural en el que nacieron, han crecido y viven las comunidades eclesiales de base, es un ambiente cminentemente propicio para que en él חorezca el pensamiento utópico. Pri-

27 Naturalmenle, los que se oponen a la utopla no se consideran "conservadores". Porque, a fin de cucntas, reconocerse conservador es aceptar inevitablemente una buena dosis de inmovilismo. por no decir de espfritu reaccionario. De ahí que quienes ponen reparos a la utopía lo suelen hacer desde consideraciones, a primera vista, sugestivas y hasta atrayentes. Un caso típico, en este sentido, es el de K. Popper, que acusa a las utopras de fanatizar a la gentc, cosa que irremediablemente termina en la violencia. Y prueba esta tesis con la historia de las dos grandes utopias que han ensangrentado el siglo $\mathrm{XX}$ : el totalitarismo comunista y el nacional-socialismo que acaudilló Hitler. Cfr. K. Popper, La sociedad abierla a sus enemigos, Barcelons, 1981. Pero aqul es importante tener en cuenta que Popper, desde su defensa a ultranza del positivismo. en definitiva, lo que hace es legitimar el sisterna establecido; eso si, con ligeros y "razonables" correctivos, pero, a fin de cuentas, manteniendo el modelo de sociedad que tenemos, incluso desde la misma comprensión de la estructura lundamental del saber y de la ciencia. Para este asunta, $c f r$. J. Habermas y olros, La disputa del positivismo en la sociología alemana, Barcelona, 1975. 
mero, porque se trata de pobres. Segundo, porque se trata de pobres no domesticados por el sistema. $\mathrm{Y}$ cuando se dan esas dos cosas juntas, inevitablemente el pensamiento, los valores y las esperanzas que se lomentan son utopía en el sentido inás estricto de la palabra. Pues bien, eso ni más ni menos es la teología que ha brotado de las comunidades eclesiales de base.

Esto explica por qué esta teología, aparentemente tan elemental y rudimentaria, ha inquictado tan seriamente a la teología tradicional. Lo cual se puede decir igualmente de la "teología de la liberación" propiantente tal. Porque, como ya dije antes y es bien sabido, la "teología de la liberación" no es sino la reflexión crítica y técnicamentc claborada, por profesionales de la teologia, a partir de la teología primera y fundante que han vivido y viven las comunidades eclesiales de base. Todos sabemos el malestar, la preocupación y el rechazo que esta teología ha suscitado en los anbientes más aferrados a la tradición teológica de siempre. No voy a repetir aquí una historia y unos hechos que son bien conocidos. Lo que sí quiero destacar es que el malestar y el rechazo, al que me acabo de referir, tienen una clave última de explicación, que no se suele reconocer, y menos aún confesar abiertamente, por parte de quienes experimentan ese malestar y cse rechazo. La clave de todo el asunto está, a mi manera de ver, no en razones teológicas o doctrinales, sino en algo que es previo a toda razón y a toda doctrina, a saber, la opción fundamentalmente utópica o anti-utópica que se tiene en la vida. Tener una opción utópica comporta dos cosas: primero, una acritud crítica frente a cómo funciona lo que hay; segundo, una propuesta de cambio para que las cosas funcionen de otra manera. Ahora bien, estas dos cosas son las que no están dispuestos a admitir, de ninguna manera, los que en la vida han tomado una opción anti-utópica. Y esto por dos razones: en primer lugar, porque eso equivaldría a reconocer que, en el fondo, están equivocados; en segundo lugar, porque eso exigiría renunciar a intereses ocultos a los que no cstán dispuestos a renunciar. Y es que, en última instancia, hablar de utopla es lo mismo que hablar de poner en cuestión lo que se tiene: posición, seguridad, privilegio, cargo, lo que sea. $Y$, en consecuencia, poner igualmente en cuestión los argumentos que legitiman y justifican eso que se tiene. De ahí que todo cspíritu anti-utópico liende a ser (por necesidad) ideológicamente conservador. Al decir esto, no pretendo insinuar que quienes tienen un talante anti-utópico sean necesariamente malas personas. Creo que el problema que aquí se plantea no es primordialmente una cuestión de ética. Por lo tanto, no me parece que sea básicamente un asunto de conciencia. Se refiere, como ya he dicho antes, al lugar epistémico que cada cual ocupa en la sociedad. Quienes viven solidariamente identificados con lo marginal del "orden establecido", inevitablemente piensan, quieren y luchan para que las cosas cambien. Quienes viven solidariamente identificados con otras cosas, personas, grupos, instituciones (por muy sagradas e intocables que se consideren), inevitablemente piensan, quieren y luchan para que las cosas sigan como están. Y esto funciona así, por más que 
los anti-utópicos pronuncien discursos o publiquen documentos diciendo que las cosas van mal y que deben mejorar. En el fondo, palabras y retóricas, que no cambian nada y que sólo sirven para confundir a los incautos.

Pero conviene analizar todo este asunto más de cerca. Se ha dicho, con toda razón, que la teología más clásica ha estado dominada por la concepción helénica del mundo y del tiempo. Su influjo quedó reflejado en la primacía de la atemporalidad ontológica, la división en los mundos sobrenatural y natural, por lo que aquél se manifiesta en la verticalidad de la revelación y, últimamente, en la supresión de la historicidad y de lo material. Dicho de otra manera, todo esto equivale a afirmar que la teología más tradicional y clásica centró sus planteamientos, sus problemas y sus soluciones en el plano de lo sobrenatural y lo eterno, con lo que la historia, la sociedad y, sobre todo, la vida concreta de la gente quedaron fuera de los intereses propia y estrictamente teologicos. De acuerdo con esta manera de enfocar las cosas, al pueblo se le dijo que lo importante es santificar el alma, aspirar a lo eterno "despreciando lo temporal" $y$, ante las adversidades de la vida, aguantar con resignación, sin alterar el "orden" que, por voluntad divina, hay que mantener a toda costa. Por supuesto, sé muy bien que, descle los años que siguieron a la segunda guerra mundial, esta manera de entender la teología fue cuestionada seriamente desde diversos puntos de vista. Y eso llevó a la profunda renovación teológica que se inció a partir del concilio Vaticano II. Todo esto es de sobra conocido. Pero tan cierto como lo anterior es que, a estas alturas, lodavía quedan en la Iglesia no pocos teólogos, centros de investigación y de enseñanza y grupos in luyentes que siguen empeñados en mantener los planteamientos de antaño, incluso los más conservadores, porque piensan (aunque no lo digan) que lo del concilio (y lo que vino después) ha sido una crisis en la Iglesia; crisis que hay que superar y olvidar cuanto antes.

Ahora bien, es evidente que cuando la teología se entiende de esta manera (que admite sus más y sus menos), se está en los antípodas de la utopía. Más aún, el teólogo que piensa así, inevitablemente ve en la utopía el peor enemigo. Lo cual se suele traducir, con cierta frecuencia, en juicios despectivos ( $\mathrm{y}$ a veces groseros) acerca de todo lo utópico. Es la manera de defender intereses (a veces inconscientes, a veces inconfensables), que dan seguridad y mantienen en el sratus rue cada cual ha conquistado en la vida, por más que todo eso se intente legitimar con razones divinas y humanas y hasta con las mas "seguras" teologías.

Pero no pensemos que, nomalmente, las cosas son así de elementales y así de descaradas. La cuestión - -tal como de hecho se ha dado en la historia de la teología- es más compleja. Dije antes que la teología más clásica ha estado do:ninata por la concepción helérica de! mundo y del tiempo. Decir esto es lo ınismo que afirınar que la teología cristiana, casi desde sus orígenes, entró en un proceso cultural o, más exactamente, se inculturó en la tradición occidental, 
marcada por el helenismo, su filosofía, su lenguaje, sus sistemas de interprelación y hasta sus leyes. La consecuencia inmediata que se siguió de este proceso de helenización es que la teología centró su interés, sus preocupaciones, sus problemas y sus soluciones en cuestiones que, de una manera o de olra, se referian siempre a lo eterno, lo intemporal, lo sobrenatural, en definiliva, lo divino. De tal manera que todo esto se consideraba como radicalmente distinto y hasta contrapuesto a lo terreno, lo temporal, lo humano, y por lo tanto, lo histórico, que siempre es contingente, mutable y perecedero. Desde el momento en que las cosas se plantearon de esa manera, la teología dejó (no tuvo mís remedio que dejar) de ser un pensamiento utópico. Porque la ulopía se plantea siempre en la hisioria y a partir del acontecer humano, donde se juega la suerte o la desgracia de los mortales, más concretamente allí donde se plantean y se resuelven (para bien o para mal) los conflictos y las luchas de los hombres y mujeres de este mundo por la juslicia y por la libertad. Pero, es claro, la teología andaba siempre ausente de estas cosas. Ella tenía otros asuntos más importantes en que pensar. Porque su problema era y es lo definitivo y último.

Sobre lo que acabo de escribir se pueden decir muchas cosas. Sobre lodo, se puede discutir interminablemente si, de facto, el desarrollo y la historia de la teología luvieron que ser así o pudieron ser de otra manera. Desde lucgo, no pienso perder el tiempo en semejante discusión. Sólo una cosa me interesa: si la teología tomó los derroteros que tomó, es porque en ella no pudieron decir nada (ni luvieron nada que decir) los pobres y marginados de este mundo. ¿Qué iban a decir esas gentes en un asunto del que nada entendían? Ya dije antes que la teología ha sido elaborada, fuera de muy contadas excepciones, por "hombres de Iglesia". Y los "hombres de Iglesia", bien lo sabemos, han sido y siguen siendo personas suficientemente situadas, incluso normalmente instaladas, en el conjunto de la sociedad. De un grupo humano así configurado, hubiera sido un milagro que resultara un pensamiento ulópico. Ocurrió lo que tenía que ocurrir: hombres bien alimentados, seguros de sí mismos y pueslos a pensar, construyeron un sin fin de teorias, que poco o nada tenían que ver con el sufrimiento y el destino de los pobres. Es más, cuando ocurrió el "milagro", quiero decir, que "hombres de Iglesia", como Campanella, escribieron sus ulopías, lodo quedó en un asunto intranscendente, que para nada in luyó cn la teología de entonces y de después.

Como es sabido, ha sido en este siglo cuando se ha producido el giro decisivo. Por una parte, en Europa, el sufrimiento acumulado de las dos guerras mundiales (a fin de cuentas, sufrimiento del pueblo) desencadenó los planteamientos de la teología de la esperanza de J. Molimann y de la teología política de J. B. Metz. Ambos planteamientos han apuntado a la utopía del reino de Dios que hay que convertir en historia. Pero, sin duda alguna, el acontecimiento tcológico determinante ha ocurrido cuando el pueblo ha lomado la palabra. Quicro Jecir: cuando los pobres se han puesto a hacer teología. Y esto ha sido en América Latina, exactamente a partir de la experiencia que han vivido y viven las comu- 
nidades eclesiales de base. Con una consecuencia que era de esperar: la teología que ha brotado de la vida, concretamente de la vida de los pobres, ha resultado sorprendente $\mathrm{e}$ inquietante. Sobre todo, sorprendente e inquietante para quienes, de una manera o de otra, constituyen los pilares del sistema, del "orden constituido". Y tambien, claro esı́, para todos los que se sienten identificados con el sistema y seguros en él. Naturalmente, donde más ha cundido la inquietud, la preocupación y el malestar ha sido en los ambientes religiosos o, más exactamente, en los ambientes eclesiásticos o clericales. A fin de cuentas, lo que está en juego es un nuevo modo de pensar la religión y todo lo relacionado con ella. Pero justamente en este punto es donde me parece más necesario y más urgente aclarar las cosas. Quiero decir: si la teología de las comunidades eclesiales de base ha inquietado y preocupado a tantas personas en los ambientes eclesiásticos, eso no se debe a que las comunidades hayan dicho herejías o hayan atacado la fe y los dogmas de la Iglesia católica. Nadie podrá demostrar que las comunidades hayan puesto en peligro esas cosas. Ni siquiera en el tema de la autoridad. Lo dije en la introducción de este artículo y lo repito ahora: las comunidades han aceptado siempre y siguen aceptando la estructura jerárquica de la Iglesia; han buscado siempre y siguen buscando la comunión y el diálogo con los obispos y con cl papa. Insisto en ello, el problema no está ahí. Entonces, ¿qué es lo que pasa? Lo diré en pocas palabras. A mi manera de ver, toda la cuestión está en que la teología de las comunidades de base es una utopía. Y eso, en concreto, significa lo siguiente: las comunidades piensan y quieren que el asunto del reino de Dios no sea solamente un tema de investigación para los estudiosos, ni solamente un tema de predicación para los oradores entusiastas, sino sobre todo y ante todo el principio organizativo determinante para el concreto funcionamiento de la lglesia. Al decir esto, estoy pensando que no se puede pedir nada ni más evangélico ni más tradicional, en el sentido más puro y limpio de lo que es la auténtica tradición de la Iglesia.

Lo que pasa es que tomar en serio (y con todas sus consecuencias) la utopía que acabo de indicar es algo que inquieta y hasta pone nerviosas a no pocas personas en los ambientes eclesiásticos y clericales. $Y$ las inquieta y pone nerviosas porque, de tomar eso en serio, serían muchas las cosas que se pondrían en cuestión. No se trala (lo diré una vez más) de poner en duda (y menos aún de negar) el principio de autoridad en la Iglesia. Sino que se trata de replantear, desde el evangelio, el modo de ejercer la autoridad. Al afirmar esto, no estoy defendiendo ni una Iglesia ácrata, ni una Iglesia demócrata, en el sentido propio de esta palabra, como poder que delega el pueblo y que, por lo tanto, viene del pueblo. No. El poder y la autoridad, en la Iglesia, vienen de Cristo. Lo que ocurre es que, con el evangelio en las manos, el poder y la autoridad en la Iglesia no se pueden ejercer según el modelo de los poderes de este mundo (cfr. Mc 10, 42-45 par.). Ni tampoco se pueden ejercer de mancra que lo que sucede, en la prácrica, es que la Iglesia, por una parte, publica documentos denunciando 
las injusticias, pero por otra parte y al inismo tiempo, mantiene muy buenas relaciones con poderes políticos y económicos, que son responsables directos de clanorosas injusticias y de sufrimienlos enormes para el pueblo. $Y$ viniendo al ámbito estrictamentc eclesiástico, me parece que el poder y la autoridad en la Iglesia no se pueden cjercer de manera que, en la próctica, se margine la palabra y la aportación de los seglares, la corresponsabilidad de los presbíteros, el diálogo en la toma de decisiones importantes, la libertad de opinar en cosas que no son de fe. Y, cn general, el poder en la Iglesia no sc puede ejercer de una mancra tan autoritaria y vertical que, en la práctica, rcsulte extremadamente difícil la comunión real de todos y con todos, incluso con aquellos que piensan de manera distinta en asuntos que no afectan al contenido de la fe. Tengo la impresión de que, en todo este asunto, en la Iglesia se confunde, con demasiada frecuencia, el origen de la autoridad con el ejercicio de esa autoridad. Y esta confusión lleva a lo sigujente: como el origen es divino, el ejercicio corre el peligro de ejercerse de manera ilimitada o, por lo menos, incontrolada. Porque ¿quién va a poner límites o control a lo divino?

Por olra partc, si efectivamente el proyecto del reino de Dios se toma como el principio organizativo determinanle para el correcto funcionamiento de la Iglesia, entonces, tendríamos que llegar a la conclusión de que el centro de la vida y de la actividad de la Iglesia no está en su organización interna, en sus derechos, en sus instituciones y en sus intereses, sino en los derechos e intereses de todos los que sufren en esta vida, sobre todo de los que sufren injustamente, que, de una manera o de otra, son ante todo y sobre todo los pobres. Pero, por desgracia, lo que ocurre es que, con demasiada frecuencia, en la Iglesia se produce el conocido y tantas veces denunciado fenómeno del "eclesiocentrismo". Es decir, los "hombres de Iglesia" (y muchas gentes allegadas a ellos) confunden, en la práctica, los intereses de la instilución eclesiástica con los intereses del reino de Dios. Y lo que resulta en concreto es que la institución se impone y sigue adelante. Pero no tanto ni con tanta frecuencia el reino que anunció Jesús.

El hecho es que, estando asf las cosas, la utopía del reino se ve reducida, con frecuencia, a teoría sobre la que discuten los expertos, pero que no se traduce, tantas y tantas veces, en praxis operativa que influye para que cambie el rumbo de esta sociedad, en la que cada día se acrecienta el sufrimiento de los pobres. Y es esto, que acabo de decir, lo que constiluye el núcleo, el centro mismo, de la teología de las comuniddes eclesiales de base.

\section{Conclusión}

En la introducción de esle trabajo formulé una pregunta que, en parte, está aún por responder. En lo dicho hasta ahora ha quedado claro que las comunidades han elaborado una teología que es utopla. Por supuesto, como ya indiqué en 
su momento, lodo esto ha sido y es un acontecimiento teológico de primera magnitud y cuyas consecuencias, para el futuro de la Iglesia, serán sin duda más decisivas de lo que algunos imaginan. Pero queda todavía una cuestión por precisar. Dije y repilo que las comunidades eclesiales de base en América Latina han permanecido 'y permanecen dentro de la más estricta ortodoxia eclesial. Entonces, ¿qué novedad teológica han aportado? $\mathrm{O}$ dicho de una manera más expresiva, ¿por qué la manera de pensar, de hablar y de vivir de estas comunidades ha preocupado e incluso ha inquietado a no pocos teólogos y jerarcas eclesiásticos? ¿Por qué se ha intentado desautorizar y hasta neutralizar esa manera de pensar, de hablar y de vivir?

A mi manera de ver, el fondo de la cuestión está en lo siguiente. El pensamiento utópico, que ha brolado de la vida de los pobres, ha venido a plantear dos pregunlas que, por una parte, han creado bastante malestar en los ambientes eclesiásticos; y, por la otra, exigen por sí mismas, en la medida de lo posible, una respuesta clara y urgente. Estas dos preguntas se refieren, la primera, a la relación de la lglesia con la sociedad; la segunda, a las relaciones que se dan en el interior de la Iglesia. Concretando más: lo primero que, en definitiva, se preguntan las comunidades es qué relación, no teórica, sino práctica y concreta, se da entre la institución eclesiástica y el dinero. Lo segundo que se preguntan es si el modo de ejercer el poder, que de hecho se practica en la lglesia, es el modo que Jesús enseñó y quiso Jesús para los cristianos.

A primera vista, serán muchos los que lendrán la impresión de que estas dos preguntas no se refieren a cuestiones propiamente teológicas, sino a asuntos que se quedan en el ámbito de la praxis. Y la praxis (bien lo sabemos), ha estado y estará siempre condicionada por la limitación humana, la pecaminosidad humana, elc., elc. A fin de cuentas, fallos de praxis, que son perfectamente comprensibles, como ocurre en todo to humano; pero, eso sí, una teología impecable, estriclamente ortodoxa y, por lo tanto, incuestionable. Pues bien, aquí precisamente es donde, según creo, está el nudo de todo el problema. Porque, ante todo, está claro que la lglesia debe tener una teología correcla sobre el dinero; y también una teología correcta sobre el poder. No olvidemos que el dinero y el poder son dos asuntos decisivos en la vida y en la sociedad. Como son igualmente decisivos en la correcta comprensión del evangelio. Pcro, por otra parte, cuando se trata de dinero y de poder, la praxis (lo que se hace) incide inevitablemente y condiciona necesariamente la teoría (lo que se cree). Si la lglesia aclúa de una manera delerminada en asuntos de dinero y de poder es porque cree que liene que acluar así. $Y$ si cree que tiene que actuar así, es porque la actuación le impulsa a tener ese convencimiento. Por lo tanto, aunque es verdad que, en cuestiones puramente especulativas, se pueden disociar la teoría y la praxis, en asuntos concrelos y práclicos (sobre lodo si son asuntos decisivos en la vida), como ocurre con el dinero y con el poder, lo que se hace no sólo es expresión de lo que se crec, sino que además determina las conviccio- 
nes e incluso las modifica, muchas veces de manera decisiva.

Pero hay más. En asunto de dinero y de poder, la Iglesia enseña, no sólo por lo que dice, sino sobre todo por lo que hace. Y esto también afecta, de manera muy directa, su teología. Quiero decir, la teología real y efectiva de la Iglesia sobre el dinero y sobre el poder no es principalmente la que aparece escrita en los documentos eclesiásticos o en los tratados teológicos, sino antes que eso y más que eso, la que resulta del funcionamiento concreto de la institución eclesiástica, en sus relaciones con los poderes políticos y económicos; y la que resulta también del modo de ejercer la autoridad con los fieles, con los clérigos en general e incluso concretamente con los obispos.

Aquí quiero aludir a cosas más concretas. En asuntos de dinero (y por lo tanto, de justicia), todos sabemos que, desde hace un siglo, la Iglesia viene enseñando una doctrina social cada vez más avanzada. En esa doctrina, se condenan las injusticias y se defiende a los pobres. Pero resulta que todo eso se queda, demasiadas veces, en lo que es, en mera doctrina. Porque, al mismo tiempo que se enseña esa doctrina, en la práctica, se mantienen excelentes relaciones con quienes cometen injusticias y oprimen a los pobres, se admiten dinero y favores de gobernantes y magnates económicos corruplos y hasta se celebra la eucaristía públicamente para hombres, instituciones y grupos que tienen las manos manchadas de sangre. $Y$ cuando digo estas cosas, cualquiera se da cuenta que me estoy refiriendo a hechos (pasados y presentes) que conoce todo el mundo. Por lo tanto, cuando hablo del problema del dinero en la Iglesia, no lo sitúo en el manoseado asunto de los bienes eclesiásticos. Y menos aún, en las habladurías que provocan ciertos clérigos por su desmedido afán de ganar dinero como sea. La cuestión es mucho más honda y mucho más grave. Es la postura de la Iglesia ante los poderes políticos y económicos. Es, por lo tanto, la libertad real que la Iglesia tiene ante esos poderes, concretamente cuando lo que está en juego es el sufrimiento de las gentes más desamparadas de este mundo. Y repito, no estoy hablando de las declaraciones teóricas y genéricas sobre la justicia y los derechos humanos. Estoy hablando de las relaciones que se mantienen con cada gobierno y con cada institución financiera, de lo que se les dice a esas pesonas y a esos grupos, y también de lo que se calla ante situaciones concretas que claman al cielo. Inevitablemente (se piense o no se piense en ello), todo esto se basa en una determinada teologla e incluso entraña una determinada teologła. Pues bien, justamente ésa es la teología que no cabe en la cabeza de los pobres. Por lo tanto, ésa es la teología que han modificado (o intentan modificar) las comunidades eclesiales de base. Aunque bien sabemos que modificar semejante teología ha traído y seguirá trayendo demasiadas complicaciones.

La segunda pregunta que se plantean las comunidades se refiere al modo de ejercer el poder en el interior de la Iglesia. De sobra sabemos que los documen-

$$
R 20322
$$


los eclesiásticos insisten reiterativamente en que la autoridad en la Iglesia es un servicio. Lo cual, muchas veces, no se queda en pura teoría. Porque afortunadamente, en los ambientes cristianos, es frecuente encontrar obispos, sacerdotes, religiosos y religiosas que son ejemplares por su entrega, a veces heroica, al servicio del pueblo de Dios. Pero el problema que plantea el ejercicio del poder en la Iglesia no es básicamente cuestión de comportamientos éticos. Quiero decir, la dificultad que experimentan muchos cristianos en ese asunto no radica fundamentalmente en que la conducta del clérigo de turno sea servicial o autoritaria. El problema está en el sisterna de gobiemo que, en la práctica, determina el modo de ejercer la autoridad en el funcionamiento de la Iglesia. No estoy hablando ni de teorías, ni siquiera de leyes. Esloy hablando de cómo funcionan, de hecho, las cosas. Por eso seguramente un par de casos concretos van a aclarar más que mil palabras.

Lo que voy a decir es conocido y está dicho con respeto para ilustrar. No hace mucho tiempo, el conocido teólogo Bernard Häring, ya jubilado y enfermo de gravedad, ha publicado un libro de memorias en el que cuenta experiencias suyas vividas en la Iglesia. Pues bien, en ese libro dice que él ha sufrido en su vida dos procesos: uno que le hizo la Gestapo, en los años atroces de la guerra mundial; y otro que le hizo, años más tarde, la Sagrada Congregación para la Doctrina de la Fe. Lo sorprendente es que este téblogo de fama internacional asegura que se le hizo más soportable y llevadero el proceso de la Gestapo que el que sufrió en las oficinas de la congregación vaticana. Y otro caso quizás más elocuente. Hace algunos años, un eminente cardenal de la Iglesia católica y además arzobispo de una diócesis importante, sin saber por qué, de pronto empezó a recibir "avisos", que venían de determinadas congregaciones de la curia romana. Un "aviso" de éslos es lo que en el lenguaje eclesiástico se suele llamar un monitum. Y los obispos saben muy bien lo que representa un monitum de Roma: es una advertencia, una llamada de atención y, de alguna manera, una reprensión, porque indica algo que hay que corregir. Naturaimente, a ningún obispo le agrada recibir un monitum. Bien, pues en el caso del cardenal al que me refiero, lo preocupante era que los "avisos" llegaban uno detrás de otro; y lo peor es que se referían a cosas intranscendentes. Ante aquella situación, el cardenal decidió ir personalmente a Roma y enterarse de lo que realmente estaba pasando. El desenlace de este caso es lo más's sorprendenie. Porque lo que el cardenal descubrió es que los "avisos" recriminatorios le venfan por causa de denuncias que mandaba a Roma un sacedote que estaba en un manicomio, y por cierto, no como capellán, sino como interno de aquel centro siquiátrico.

Parece inentira que, en un artículo teológico, haya que contar cosas de este tipo. Si lo hago es porque me parece que sólo de esta manera nos podernos hacer una idea de lo que he querido decir cuando he afirmado que el problema que plantea el ejercicio del poder en la Iglesia no es básicamente ni una cuestión de ideas, ni un asunto de leyes, ni siquiera un problema de buenas o malas 
voluntades. Insisto en que estoy hablando de cómo funcionan, de hecho, las cosas. Y el hecho es que en la Iglesia, cuando está en juego el asunto del poder, las cosas funcionan de manera tan centralizada, vertical y autoritaria que se llega a casos y situaciones como las que acabo de indicar. Esta manera de ejercer la autoridad supone una teología y se basa en una teología. Una teología no reconocida conscientemente, porque los hechos que he contado no se pueden justificar desde ninguna teología. Y en ese sentido he dicho que no es cuestión de ideas. Pero es una praxis que inconscientemente confunde, como ya apunté antes. el origen del poder con el ejercicio del poder. Y ésa es precisamente la Ieología (implícita) que inuchos cristianos no entienden y que, por supuesto, los pobres no pueden integrar en su manera de entender a Dios y la lglesia.

Termino ya. Empecé preguntando si el fenómeno de las comunidades de base en la Iglesia está de vuelta. Es decir, si todo eso de las comunidades ha sido una moda pasajera, que tiene los días contados. Mi conclusión sobre este asunto es muy clara: mientras haya pobres en la tierra y mientras haya pobres que no se integran en el sistema, tendremos hombres y mujeres que, no sólo individualmente, sino además grupalmente (y por lo tanto comunitariamente), piensen su le desde la vida. que piensen sus convicciones y esperanzas desde su condición de pobres, y que piensen su futuro desde la utopía. Eso exactamente es lo que este trabajo hal querido demostrar. A parlir de eso, los problemas del dinero y del poder, tal como existen en la Iglesia, serán planteados y resueltos cada día más y más, de acuerdo con el proyecto del reino, que es, como sabemos, el centro mismo del mensaje de Jesús. 